\title{
Therapeutic Management in a Tortoise Affected Concurrently with Metabolic Bone Disease and Respiratory Infection-A Case Report
}

\author{
Rajkumar Patel $^{1 *}$ and Rajesh Patel ${ }^{2}$ \\ ${ }^{1}$ Veterinary Officer, Prayojna Vahivatdar Shri Kachari, Khedbhrama Gujarat, India \\ ${ }^{2}$ Dr. Shyama Prasad Mukharjee Municipal Zoo, Surat, Gujarat, India \\ *Corresponding author
}

\begin{abstract}
A B S T R A C T
In India, large population of tortoise are reported to have chronic respiratory diseases, which has been responsible for high morbidity and low mortality rates in chelonians. The present report describes a case of Chronic respiratory and Metabolic Bone disease in a 4month-old Indian tortoise (G. elegans). The predisposing factor for illness was poor husbandry and maintenance of the animal. The animal was presented with chief complaint of trouble in breathing and anorexia. The tortoise chiefly showed signs of tenacious mucoid bubbling to mucopurulent discharge from the nose, palpebral edema, and dyspnoea that lasted for 20 days. The Dorso-ventral radiograph revealed affection of the lung and abdominal cavity. Along with that the animal also had marbled appearance of the vertebral and costal scutes. The shell of the tortoise was soft and deformed. The case was critical, and the animal had thin chances of survival. Due to metabolic bone disease and chronic respiratory disease, animal should have succumbed to an uneventful death. however, timely management and therapy of animal protected it from disease as it was treated and managed with Enrofloxacin @ 5mg/kg given subcutaneously in rounds of 24 hr for 1 week along with antibiotic-steroid combination ophthalmic solution through nasal cavity. The tortoise responded to the medication well and recovered in 10 days.
\end{abstract}

\section{Introduction}

The last decade has seen a trend of tortoises being increasingly kept domesticated in urban families. However, this may cause many health problems. Unhealth temperatures and poor ventilation cause weakening in tortoises' immune function and predisposes them to opportunistic organisms like Mycoplasma and Herpesvirus which can lead to the symptom of upper respiratory tract disease (Kolesnik et al., 2017). This a widespread disease among chelonians, and its symptoms are difficulty in breathing, conjunctivitis, mild to severe nasal and ocular discharge, and periocular edema. Because tortoises lack a muscular diaphragm, they cannot cough. Thus, once infection develops the tortoise cannot cough up infected material from within the lungs, and so infection tends to accumulate and make matters exacerbate. To add to the trouble -Environmental stress, hypovitaminosis A and 
D, exposure to heavy metals, impact by humans and other toxicants, captivity, etc are predisposing factors that most likely contribute to metabolic disease that often occurs with conjunctivitis (Sandmeier et al., 2013). Hypovitaminosis A disturbs the normal function of skin or organs most frequently by blocking fluid flow through ducts that lead to mucosal hyperplasia and loss of ciliated epithelium which triggers an invasion of an opportunistic pathogen like mycoplasma and infiltration of lymphocytes and histiocytes (Jacobson et al., 1991). The lesions slough large amounts of epithelial and inflammatory cells, which create the nasal discharge and over time that obstructs the nasal sinus (Wendland et al., 2006).

\section{History}

A 4-month-old Indian star ( $G$. elegans $)$ tortoise weighing 13 gram (Fig. 1) was presented with a history of tenacious mucoid bubbling to mucopurulent discharge from nose, yawning, palpebral edema and dyspnoea for 20 days. An infected tortoise has weight loss and does not want to eat. Another tortoise of similar age and body weight kept together had similar complaints. The animal was fed pelleted commercial tortoise diet available in the market.

\section{Clinical examination and diagnosis}

Clinical examination of tortoise revealed stomatitis, glossitis, the presence of mucoid discharge deposited in form of dry, viscous material over the head, increase respiration at rest. During respiration the limb movements more exaggerated and respiratory noises are audible. Eye and eyelid are swollen and discharge from both eyes seen. Since tortoise was very small, blood and other samples for laboratory examination could not be collected. Radiography was performed to rule out other causes for nasal discharge like foreign bodies and oronasal fistulas. A dorsoventral radiograph revealed affection of the lung and abdominal cavity (Fig. 2). There is a presence of fluid in the lung field. We have also found that the outlines of the vertebrae were unclear, but the shape of each vertebra was preserved. The trabeculae of the spongy bone tissue were enlarged due to ongoing bone tissue rarefaction and the most evident change of bone tissue macrostructure was the granular and marbled appearance of the vertebral and costal scutes. Unlike mammals, Diaphragm is absent in tortoise, so there is no demarcation between the thoracic and abdominal cavity. On the basis of clinical finding and radiography, the disease was diagnosed as chronic respiratory disease with metabolic bone disease and clinical treatment undertaken.

\section{Treatment and its management}

The goal of treatment for an infected tortoise is to able to function normally. So on, a combination of long-term antibiotic injections and antibiotic-steroid ophthalmic drop are used to lower inflammatory response. The present case was successfully managed with a parenteral injection of Enrofloxacin @ $5 \mathrm{mg} / \mathrm{kg}$ intramuscular once daily for 7 days followed by orally Enrofloxacin @ 5mg/kg every $24 \mathrm{hr}$ for 7 days. It is vital to keep the tortoise at a higher temperature for the duration of treatment, this speed up metabolism and drug distribution and also boosts the animal's immune system. A temperature of around 28-30 degrees is usually recommended. Ciplox- D eye and ear drop (containing ciprofloxacin and dexamethasone combination) was applied directly to external nare once a day for 10 days. The owner was advised to first wipe the animal's nose with a disposable paper towel to remove as much mucus as possible. then instill one drop of antibiotic into each nostril once daily whilst holding the animal in an 
upright position. Vemeral (containing multivitamin) one drop orally once daily for 10 days. On the 5th day, animal responded to treatment and eating as usual. The respiration gradually decreases and become normal after treatment. On the 8th day, Mark improvement noticed, and No nasal discharge was seen.

Following husbandry related guidelines provided to the owner for managing their tortoise:

The owner was advised to provide vegetable like a carrot, spinach.
The owner was advised to keep the animal in sunlight at least $1 \mathrm{hr}$. daily in the morning.

The owner was advised to soak the animal in clean shallow warm water two or three times a day for 20 minutes to keep them hydrated.

The owner was advised to provide extra calcium in the form of calcium carbonate powder.

The owner has advised keeping a thermostatically controlled environment with a temperature gradient of $24-35^{\circ} \mathrm{C}$ (75-95 $\left.{ }^{\circ} \mathrm{F}\right)$.

Fig.1 Indian star tortoise with nasal discharge from nose and bilateral palpebral edema

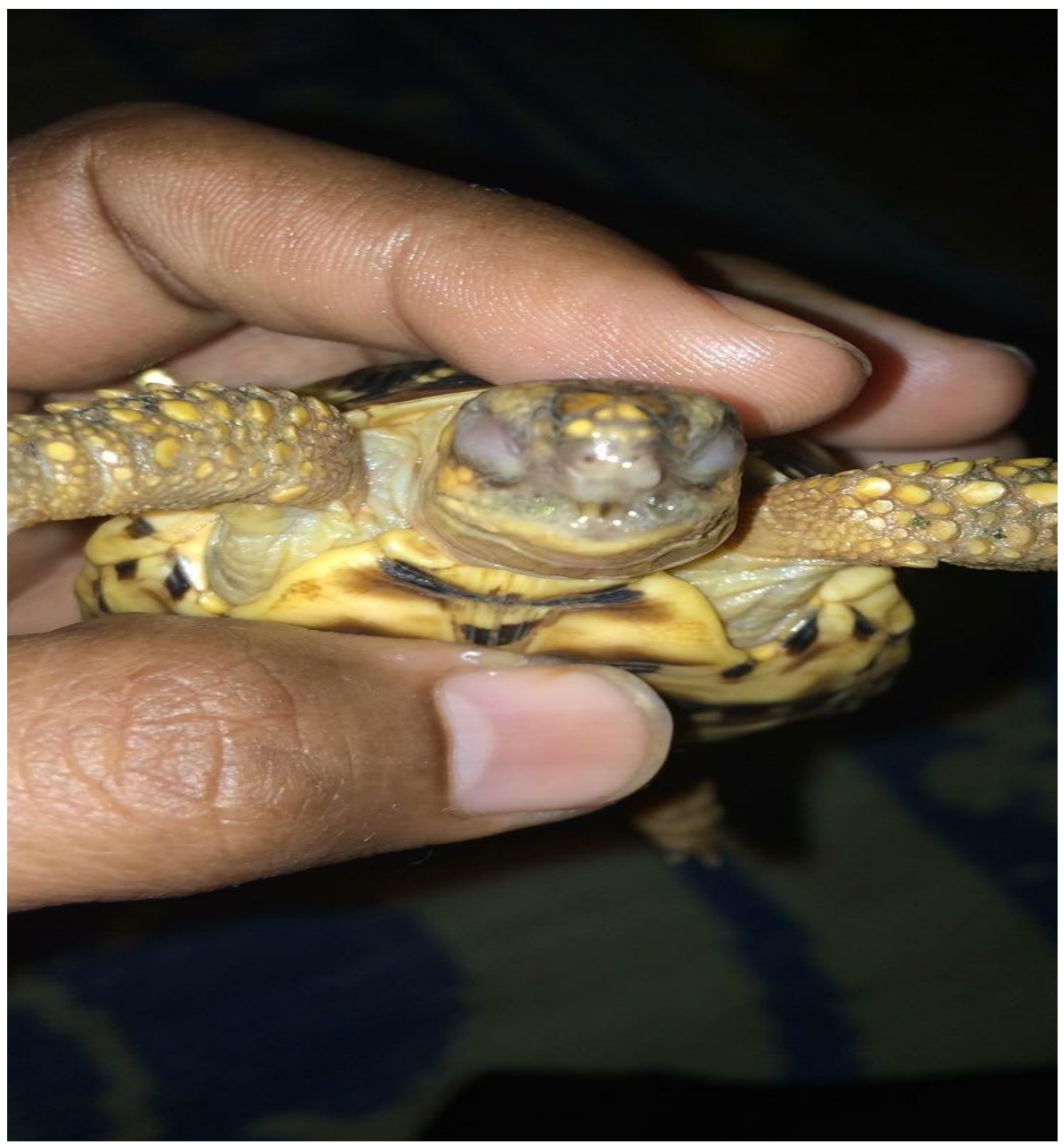


Fig. 2 X- ray of tortoise with affection of lung and abdominal cavity

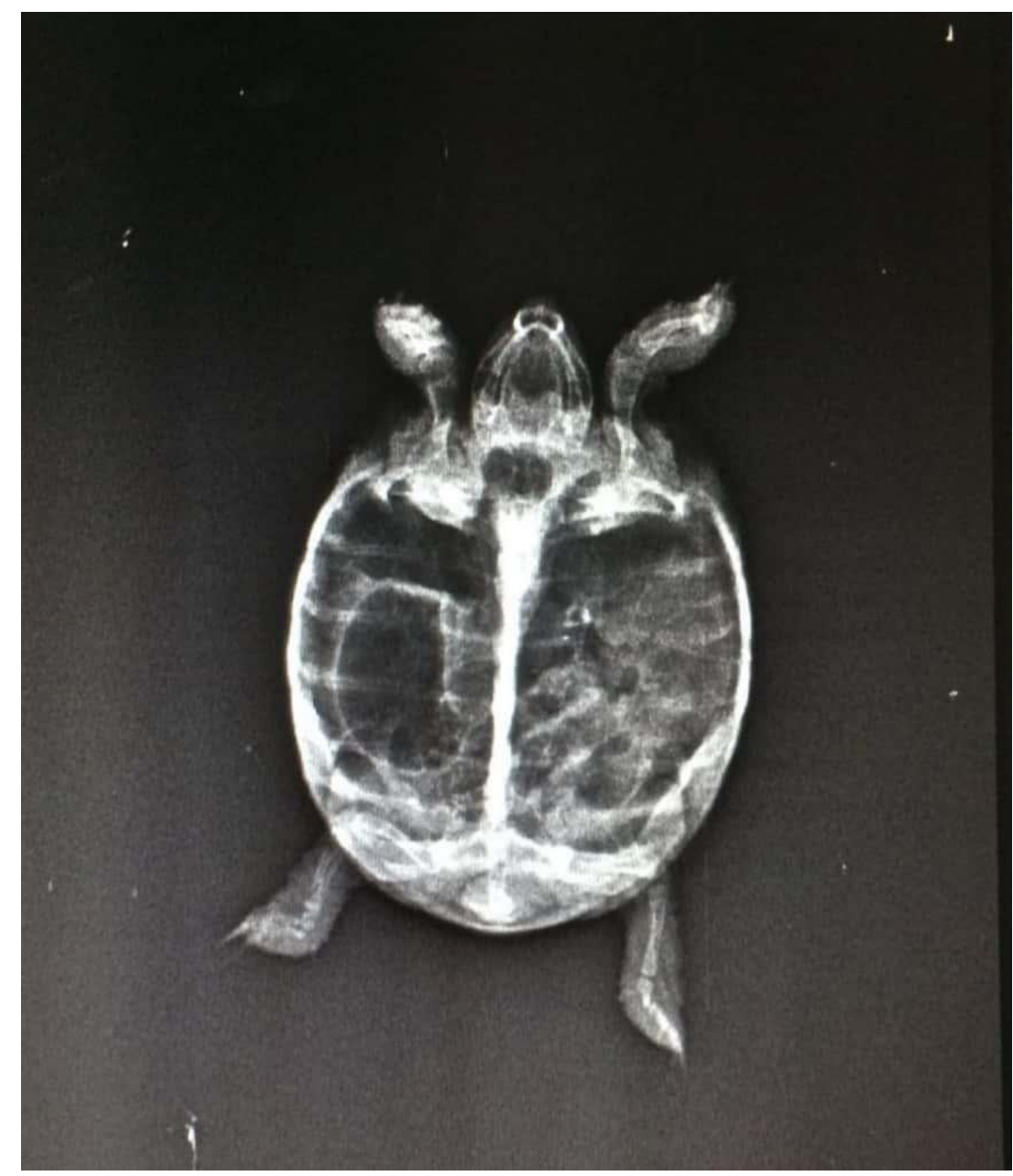

When it comes to captive tortoise, husbandry related problem commonly arises due to poor management with regards to inappropriate, humidity, temperature, lighting, and nutrition (Adkesson et al., 2007). An optimal temperature range for thermo-regulation is crucial for the welfare of tortoises, unlike other reptiles. Failure to do so can play a significant role in many diseases and acute problems like life-threatening respiratory infections and chronic disorders like shell deformities. Respiratory tract disease and Metabolic bone disease are frequently encountered in juvenile chelones. In some cases, palpebral edema, stomatitis, glossitis, conjunctivitis and nasal and ocular discharges are seen which is mostly accompanied with herpes virus infection. Similar clinical signs were observed by (Origgi et al., 2006). However, in our case, constipation was observed due to low calcium as it affects GIT motility. As the tortoise was very small, blood and other samples for were difficult to be collected for laboratory examination. Radiography was performed along with the presence of fluid in the lung we also found that the outlines of vertebrae were unclear with marbled appearance of the vertebral and costal scutes. The shell of the tortoise became soft and deformed, this put pressure on the internal organs like the lungs worsening the respiratory distress. The noticeable signs recorded in this case were in accordance to earlier reports made by Williams (2003) who 
stated that in chelonians lack of immunity and vitamin deficiencies (hypovitaminosis A and D) are the risk factors that most likely contributed to metabolic diseases that often occur with conjunctivitis. Rapheal et al., (1994) suggested that $5 \mathrm{mg} / \mathrm{kg}$ Enrofloxacin IM q $24 \mathrm{hr}$ effective in the treatment of aerobic bacterial infection in Indian star tortoise. Jacobson et al., (1994) found that the use of gentamicin- betamethasone ophthalmic drop applied directly to external nares seem to result in a significantly lower recurrence rate of clinical disease. Thus, a combination of long-term antibiotic injections and antibioticsteroid ophthalmic drop are prescribed in regards. (Khan and Line, 2005) assume that Hypovitaminosis $\mathrm{A}$ is the most common predisposing factor for pneumonia in tortoise and is frequently seen in tortoise reared as a pet. So, supplementation of Vitamin A is essential for clinical recovery from chronic respiratory disease. Here, multivitamin preparation also was prescribed in this regard. The most common reason a turtle or tortoise gets a respiratory infection is due to its environment being too cold and wet which might be due to an impact on the host immune system. Hence, the proper temperatures, diet, and lighting were instituted in the overall treatment plan.

\section{References}

Adkesson, M. J., Travis, E. K., Weber, M. A., Kirby, J. P., and Junge, R. E. 2007. Vacuum-assisted closure for treatment of a deep shell abscess and osteomyelitis in a tortoise. Journal of the American Veterinary Medical Association, 231(8), 1249-1254.

Jacobson ER, Brown MB, Wendland LD, Brown DR, Klein PA, Christopher MM, Berry KH. 2014. Mycoplasmosis and upper respiratory tract disease of tortoises: A review and update. The Veterinary Journal. 201(3): 257-264.
Jacobson, E.R., Gaskin, J.M., Brown, M.B., Harris, R.K., Gardiner, C.H., LaPointe, J.L., Adams, H.P., Reggiardo, C.1991. Chronic upper respiratory tract disease of free ranging desert tortoises, Xerobates agassizii. Journal of Wildlife Diseases. 27: 296-316.

Johnson, J.D., Mangone, B., and Jarchow, J.L. 1994. A review of mycoplasmosis infections in tortoises and options for treatment. Proc ARAV, 89.

Khan, C.M., Line, S. The Merck Veterinary Manual, $10^{\text {th }}$ Edn., Whitehouse Station, N. J., USA. Merck and Co. Inc.; 2005.

Kolesnik, E., Obiegala, A., and Marschang, R.E. 2017. Detection of Mycoplasma spp., herpesviruses, topiviruses, and ferlaviruses in samples from chelonians in Europe. Journal of Veterinary Diagnostic Investigation. 29, 6: 820-832.

McArthur, S., Windsor, H., Bradbury, J.M., Yavari, C.A.: Isolation of Mycoplasma agassizii from UK captive Chelonians (Testudo horsfieldii and Geochelone pardalis) with upper respiratory tract disease. 2002. In: Proceedings of the 14th International Congress of the International Organization for Mycoplasmology, Vienna, Austria. Pp. 7-12.

Muro, J., Ramis, A., Pastor, J., Velarde, L., Tarres, J., Lavin, S. et al., 1998. Chronic rhinitis associated with herpesviral infection in captive spurthighed tortoises from Spain. Journal of Wildlife Disease 34:487495.

Origgi, F., Herpesvirus in tortoises. 2006. In: Mader DR, ed. Reptile Medicine and Surgery. 2nd ed. St Louis, MO: Saunders Elsevier; pp. 814-821.

Raphael, B.L., Papich, M., and Cook, R.A.1994. Pharmacokinetics of 
enrofloxacin after a single intramuscular injection in Indian star tortoises (Geochelone elegans). Journal of Zoo and Wildlife Medicine. 25(1): 88-94.

Sandmeier, F.C., Tracy, C.R., Hagerty, B.E., DuPré, S., Mohammadpour, H., Hunter et 2013. Mycoplasmal upper respiratory tract disease across the range of the threatened Mojave Desert
Tortoise: Associations with thermal regime and natural antibodies. EcoHealth. 10: 63-71.

Wendland, L., Brown, D., Klein, P., Brow, M.: Upper respiratory tract disease (Mycoplasmosis) in tortoises. 2006 In Mader DR (editor). Reptile Medicine and Surgery, 2nd Ed. Saunders Elsevier, St Louis, MO. pp. 931-938.

\section{How to cite this article:}

Rajkumar Patel and Rajesh Patel. 2020. Therapeutic Management in a Tortoise Affected Concurrently with Metabolic Bone Disease and Respiratory Infection-A Case Report. Int.J.Curr.Microbiol.App.Sci. 9(10): 792-797. doi: https://doi.org/10.20546/ijcmas.2020.910.095 